\title{
Phenolic content, antioxidant and anti-inflammatory activities of some Algerian olive stone extracts obtained by conventional solvent and microwave-assisted extractions under optimized conditions
}

\author{
Kenza Djemaa-Landri ${ }^{1}$. Sabrina Hamri-Zeghichi ${ }^{1}$. Wassila Belkhiri-Beder ${ }^{1,5} \cdot$ Stéphanie Krisa $^{2} \cdot$ Stéphanie Cluzet $^{2}$. \\ Tristan Richard ${ }^{2} \cdot$ Josep Valls ${ }^{2} \cdot$ Nabil Kadri $^{1,3}$ (D) Khodir Madani ${ }^{4}$
}

Received: 20 February 2021 / Accepted: 1 June 2021 / Published online: 8 June 2021

(c) The Author(s), under exclusive licence to Springer Science+Business Media, LLC, part of Springer Nature 2021

\begin{abstract}
The recovery of food waste is a stimulating opportunity for and competitive development of agroindustries. In this context, the objective of this study was to report the antioxidant potential and phenolic compounds content of olive stones (OS) of six Algerian cultivars. Two extraction methods were used: microwave assisted extraction (MAE) and conventional solvent extraction (CSE) in order to improve the recovery of total phenolic content (TPC) and the maximization of the two extraction processes by the Box-Behnken design (BBD) from olive stone of Olea Europaea L. cv Ayemele. The optimal processing parameters obtained were (i) for MAE: $22 \%(\mathrm{v} / \mathrm{v})$ ethanol, $40 \mathrm{~s}, 500 \mathrm{~W}$, and ratio 65:1 (mL/g) and (ii) for CSE: $33 \%(\mathrm{v} / \mathrm{v})$ ethanol, $24 \mathrm{~min}, 71{ }^{\circ} \mathrm{C}$, and ratio $60: 1(\mathrm{~mL} / \mathrm{g})$. Phenolic compounds were then extracted from olive stones of six Algerian cultivars with MAE best extraction conditions, as it was the best strategy in term of TPC recovery. The phenolic content was different according to the olive variety. The stones of Chemlale were the richest in TPC $(7.23 \mathrm{mg}$ GAE/g) followed by Azeboudj (6.33 mg GAE/g), Atefah (6.04 mg GAE/g), Agraraz (5.63 mg GAE/g), Azeradj (5.35 mg GAE/g) and Ayemel (5.14 mg GAE/g). A similar profile was observed with total flavonoids content and antioxidant activities. The anti-inflammatory effects of the optimized extracts by MAE were assessed regarding their ability to prevent lipopolysaccharide-induced of reactive oxygen species and nitric oxide production in a macrophage cell line (RAW 264.7). Olive stones that are issued from the production of olive oil, and table olives can therefore be considered as renewable by-products thanks to their compounds with high added value. These bioactive compounds can target the food natural additives markets, pharmaceutical and cosmetic industries, all of which are currently very receptive such natural products.
\end{abstract}

Nabil Kadri

kadri.montp2@gmail.com

1 Laboratoire de Biomathématique, Biophysique, Biochimie, et Scientométrie, Faculté des Sciences de la Nature et de la Vie, Université de Bejaia, 06000 Bejaia, Algérie

2 Univ. Bordeaux, Faculté des Sciences Pharmaceutiques, Unité de Recherche Enologie, EA 4577, USC 1366 INRAE, Equipe Molécules d'Intérêt Biologique (MIB) - ISVV, 33882 Villenave d'Ornon cedex, France

3 Département des Sciences Biologiques, Faculté des Sciences de la Nature et de la Vie et des Sciences de la Terre, Université de Bouira, Bouira, Algérie

4 Centre National de Recherche en Technologie de l'Agroalimentaire (CRTA), 06000 Bejaia, Algérie

5 Département de Génie des Procédés, Faculté de Technologie, Université de Bejaia, Bejaia, Algérie 


\section{Graphic abstract}
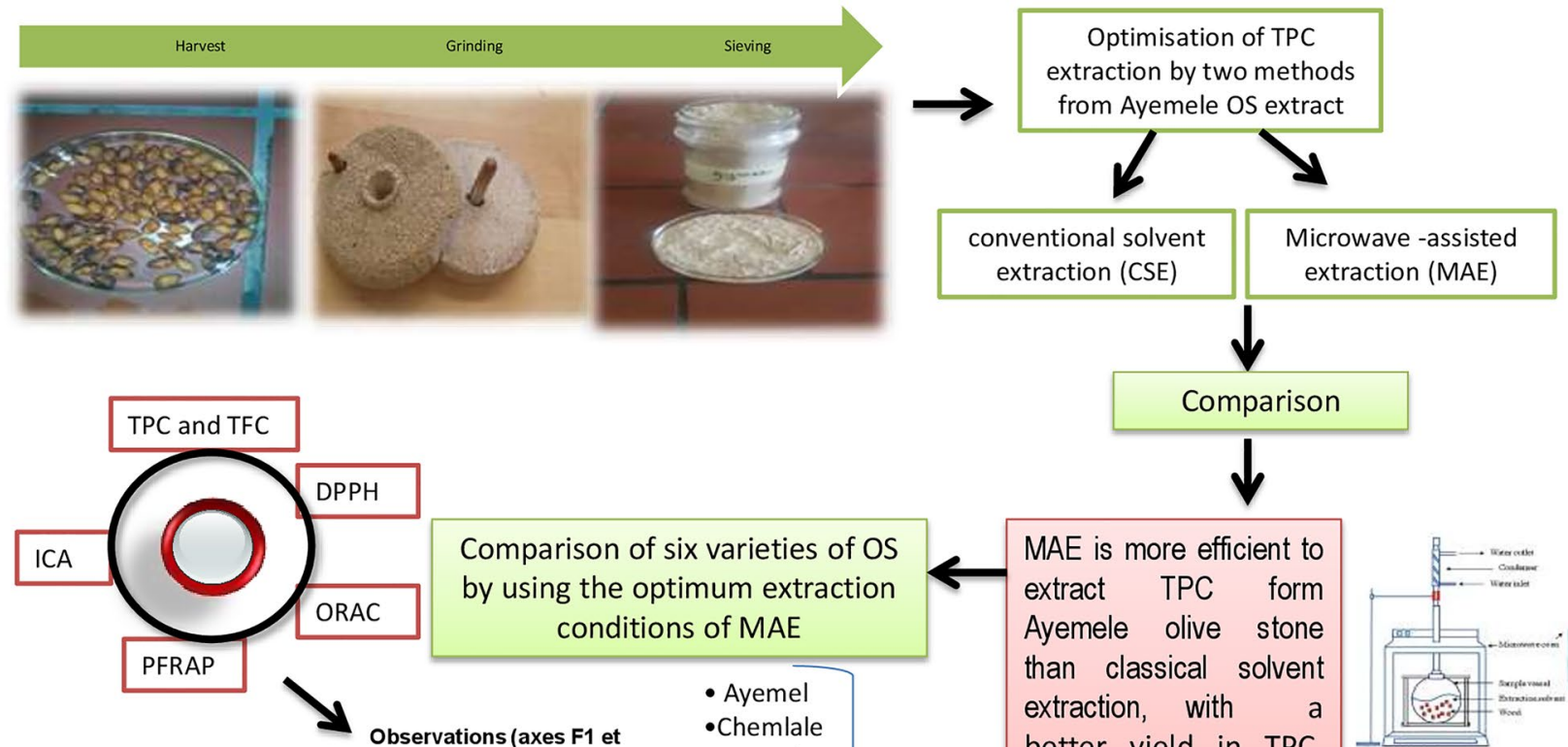

Comparison of six varieties of OS

RAC

by using the optimum extraction conditions of MAE
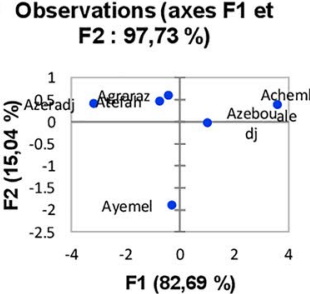

- Ayemel

- Chemlale

- Azeradj

- Agraraz

- Atefah

-Azeboudj
Comparison

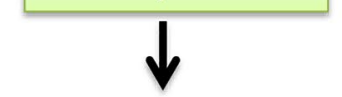

MAE is more efficient to

extract TPC form Ayemele olive stone than classical solvent extraction, with a better yield in TPC, TFC and antioxidant activity by avoiding water and solvent consumption, with lower time of procedure.

Keywords Response surface methodology $\cdot$ Phenolic compounds $\cdot$ Extraction methods $\cdot$ Antioxidant activity $\cdot$ Optimization

\section{Introduction}

Several studies have revealed a low incidence of many sicknesses among populations in the Mediterranean region such as heart disease and certain cancers [1, 2]. It has been often suggested that this reduced incidence of diseases can be related to a high consumption of fruits, vegetables and fats [3]. In the Mediterranean diet, olive oil is the main origin of fat in daily dishes and salads. The olive tree belongs to the Oleaceae family and the genus Olea, which includes about thirty different species in the world [4]. This tree is present in all four continents, and various cultivars are enumerated in Algeria. Nowadays, the Algerian varieties "Hamma", "Chemlale", "Azeradje", "Bouchouk", "Rougette", "Blanquette", and "Ayemele" are predominated in the center and in the east [5]. The beneficial effect of olive on human health can be attributed, among its valuable components, to its composition in polyphenols. In olive fruit, various phenolic forms have been reported: simple phenolic acids like coumaric acid derivatives [6], flavonoids, phenolic oleosides and phenolic glucosides [7-9]. The phenolic compounds of olive oil represent only $2 \%$ of the phenolic compounds of whole olives. The majority (98\%) of compounds are found in olive mill waste [10]. The utilization of by-products collected from plants for food application presents indisputable advantages, as it constitutes an environmentally friendly processing route, since, as instance, it greatly simplifies waste disposal management strategies $[11,12]$. Few works have described the potential of polyphenols contained in the olive cake in the field of pharmacy [10]. The olive pulp phenolic content has been evaluated and reviewed more than other fractions of the plant [13-15].

Many new extraction procedures have been initiated and investigated, such as ultrasound-assisted extraction, microwave-assisted extraction, pressurized liquid extraction, and pressurized hot water extraction [16], most of which are claimed to improve efficiency, extract quality, extraction time and solvent consumption. One of the most promising emerging techniques of extraction is based on microwaves use [17]. While few studies have focused on the chemical 
constitution of Algerian olive oil varieties, no work has emphasized the optimization of polyphenols from olive stone (OS) grown in Algeria. We targeted in this work the following points: (1) examine the effects of several parameters on the extraction efficiency of total phenolic content (TPC) by microwave assisted extraction (MAE), (2) optimize their extraction conditions by Box-Behnken Design (BBD), (3) compare the optimized MAE with Conventional Solvent Extraction (CSE) process, and (4) compare six varieties of olive stones in terms of total phenolic content, total flavonoid content, antioxidant and anti-inflammatory activities.

\section{Materials and methods}

\section{Reagents and standards}

Folin-Ciocalteu's phenol reagent, sodium carbonate ( $\geq 99.5 \%$ ), Iron(II) sulphate ( $\geq 99.0 \%$ ), aluminum chloride ( $\geq 99.0 \%), 2,2^{\prime}$-azobis(2-methylpropionamidine) dihydrochloride (AAPH), 6-hydroxy-2,5,7,8-tetramethylchromane2-carboxylic acid (Trolox, 97\%), potassium ferricyanide $(\geq 99.0 \%)$, trichloroacetic acid ( $\geq 99.0 \%)$, ferric chloride ( $\geq 99.9 \%), 3$-(2-Pyridyl)-5,6-diphenyl-1,2,4-triazine-4',4"disulfonic acid sodium salt (ferrozine, $\geq 97.0 \%$ ), 2,2-Diphenyl-1-picrylhydrazyl (DPPH), fluorescein ( $\geq 95.0 \%)$, dimethyl sulfoxide (DMSO, $\geq 99.7 \%$ ), L-glutamine ( $\geq 99.0 \%$ ), fetal horse serum, fetal bovine serum, 3-(4,5-dimethylthiazol-2-yl)-2,5-diphenyl tetrazolium bromide (MTT, $\geq 98.0 \%)$ ), Griess nitrite reagent, phosphate buffer (1 M, pH 7.4), L-ascorbic acid ( $\geq 99.0 \%)$ and lipopolysaccharide (LPS) were provided from Sigma-Aldrich (France). Acetonitrile (UHPLC grade) and disodium ethylenediaminetetraacetate dihydrate (EDTA, $\geq 99.0 \%$ ) were supplied by Fisher Scientific (France). Methanol (HPLC grade) and ferrous sulfate heptahydrate were supplied by Prolabo (France). Ultapure water (resistivity $\geq 18 \mathrm{M} \Omega / \mathrm{cm}$ ) was procured using an ELGA water purification system (ELGA LabWater, United Kingdom).

\section{Material preparation}

Olive drupes of Olea europaea L. were harvested in October 2016, in Ighil Nacer, Akbou, Bejaia province of Algeria. Samples of whole olives were taken randomly, from several olive trees of Ayemel, Achemlal, Azeradj, Agraraz, Atefah, and Azeboudj varieties. Sample identification was performed by a botanist from the laboratory of biology and plant physiology from Bejaia University. The olives were cleaned, set free of impurities and husked manually to recover the stones, then dried at ambient temperature in a ventilated darkroom for about seven days, and then ground in a traditional grinder. The obtained powder was passed through an electric sieve (Retsch As 200, Haan, Germany) having an upwards porosity of $500 \mu \mathrm{m}, 250$ and 125 . The powders were stored at room temperature, and protected from light and humidity in a hermetic and opaque container until use.

\section{Procedure of extraction}

\section{Microwave-assisted extraction (MAE)}

Phenolic compounds were extracted from OS cv Ayemel using a domestic microwave oven system (Maxipower Model MAXMO23S, Shenzhen, Guangdong, China) with adjustable nominal power output (100-1000 W). The device oven has been modified in our laboratory to condense vapors generated during extraction into the samples. One gram of OS powder was mixed with $20 \mathrm{~mL}$ of extraction solvent, and irradiated in the microwave oven at prefixed time and power. The suspension was filtered across a Whatman No. 1 filter paper (USA), and then collected at $4{ }^{\circ} \mathrm{C}$ until further analysis.

\section{Conventional solvent extraction (CSE)}

The OS powder of Ayemel variety was subjected to extraction by maceration following the technique described by Safdar and Kausar [18], with slight modifications. One gram of OS powder was mixed with $20 \mathrm{~mL}$ of extraction solvent, in a conical flask, and the mixture was kept in a thermostatic water bath (Memmert type-ONE 7, Schwabach, Germany) at prefixed time and temperature. The samples were filtrated via a Whatman No. 1 filter paper (USA) and stored at $4{ }^{\circ} \mathrm{C}$.

\section{Optimization of the extraction procedures}

For the optimization procedure, the influence of the process parameters were first investigated separately in single factor experiments to limit the total experimental work (Tables 1, 3 ), and then the most influencing factors were selected. After that, an RSM based on a Box-Behnken experimental design (BBD) was conducted to optimize both methods with the application of four factors (ethanol concentration $(\%, \mathrm{v} / \mathrm{v})$, temperature $\left({ }^{\circ} \mathrm{C}\right)$, time (min), and liquid-to-solid ratio (mL:g) for CSE and ethanol concentration (\%, v/v), microwave power (W), irradiation time (sec), and liquid-tosolid ratio (mL:g) for MAE) at three levels $(-1,0$ and +1$)$. The BBD plan included 27 tests with a centric $(0,0,0)$ test repeated three times to verify the standard error and reproducibility of the extraction process. 


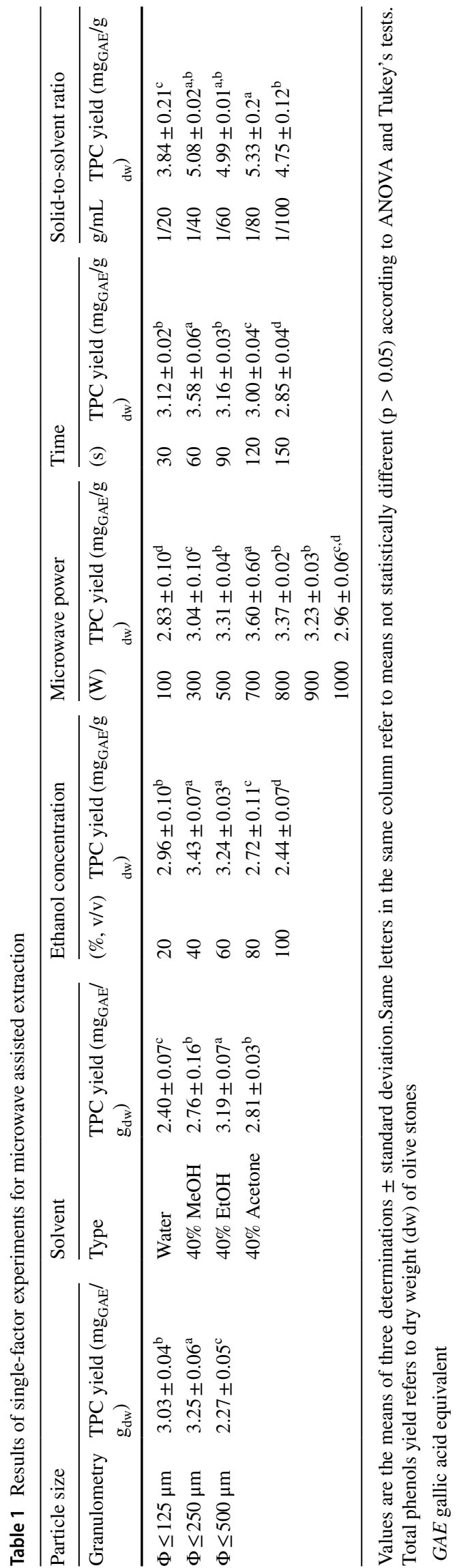

\section{Analysis of total polyphenols}

Total phenolic content (TPC) was assessed using the Folin-Ciocalteu method [19]. Thus, $2.5 \mathrm{~mL}$ of waterdiluted Folin-Ciolcateu's phenol reagent (1/10) was added to $500 \mu \mathrm{L}$ of extract. Two minutes later, $2 \mathrm{~mL}$ of sodium carbonate $(75 \mathrm{~g} / \mathrm{L})$ was added. After incubation for $15 \mathrm{~min}$ at $50{ }^{\circ} \mathrm{C}$, the specific absorbance at $760 \mathrm{~nm}$ was immediately measured using a UV-Visible light spectrophotometer (UV-Vis Spectrophotometer, SHIMADZU, Kyoto, Japan). TPC concentration was calculated from a calibration curve $(y=4,735 x+0,0268)$, adopting gallic acid as an external standard and results were expressed as mg gallic acid equivalents (GAE) per gram of dry powder. Triplicate assays were made for all determinations.

\section{Determination of flavonoids content}

Total flavonoids content (TFC) was determined according to the method of Djeridane et al. [20]. One $\mathrm{mL}$ of $2 \%$ aluminum chloride methanol solution was mixed with $1 \mathrm{~mL}$ of extract and then mixed using a vortex stirrer (VELP Scientifica, Usmate, Italy) for approximately $10 \mathrm{~s}$, and left for $15 \mathrm{~min}$. Compounds were quantified by reading absorbance at $430 \mathrm{~nm}$ using UV-vis light spectrophotometer (UV-VIS Spectrophotometer, SHIMADZU, Kyoto, Japan). TFC was expressed as $\mathrm{mg}$ quercetin equivalent per $\mathrm{g}$ of powder $(\mathrm{mg}$ $\mathrm{QE} / \mathrm{g}$ ). Each OS extract was tested three times.

\section{Determination of the extracts antioxidant activities}

\section{DPPH assessment}

The DPPH test of OS extracts was carried out by the procedure depicted by Blois, 1958 [21] with some modifications. We added $50 \mu \mathrm{L}$ of extract to $150 \mu \mathrm{L}$ of methanolic DPPH solution $(200 \mu \mathrm{M})$ in a 96-well plate, which was left in the dark at room temperature for $20 \mathrm{~min}$. The absorbance decrease was measured at $520 \mathrm{~nm}$ with a Fluostar Optima plate reader. Results were calibrated with a standard Trolox curve $(\mathrm{y}=-0.015+0.8221)$, and expressed in $\mathrm{mg}$ Trolox equivalent per gram of dry mass (mg TE/g). Analyses were performed in triplicate.

\section{The oxygen radical absorbance capacity estimation (ORAC)}

The ORAC of the different extracts was measured following a previous methodology [22] using a plate reader (Fluostar Optima). Briefly, $30 \mu \mathrm{L}$ of extract sample diluted in phosphate buffer at $\mathrm{pH} 7.4$ were placed into black 96-well plates, and $180 \mu \mathrm{L}$ of fluorescein solution $(70 \mathrm{nM})$ was added. After 10 min preincubation at $37^{\circ} \mathrm{C}, 90 \mu \mathrm{L}$ of AAPH solution $(12 \mathrm{mM})$ was added, and fluorescence was recorded 
using $485 \mathrm{~nm}$ excitation and $530 \mathrm{~nm}$ emission wavelengths for 60 min against a blank sample $(30 \mu \mathrm{L}$ phosphate buffer). ORAC measurements were stated as mg of Trolox equivalent/g of dry mass (mg TE/g). All OS extracts were examined in triplicate.

\section{The potassium ferricyanide reducing antioxidant power test (PFRAP)}

The PFRAP of OS samples was assayed with the outlined procedure of Oyaizu [23]. To $1 \mathrm{~mL}$ of sample extracts, $2.5 \mathrm{~mL}$ phosphate buffer $(0.2 \mathrm{M}, \mathrm{pH} 6.6)$ and $2.5 \mathrm{~mL}$ potassium ferricyanide $(1 \%, \mathrm{w} / \mathrm{v})$ were added. After incubation at $50{ }^{\circ} \mathrm{C}$ for $20 \mathrm{~min}, 2.5 \mathrm{~mL}$ trichloroacetic acid $(10 \%$, w/v) was added. Two and one half $\mathrm{mL}$ of this mixture were then mixed with $2.5 \mathrm{~mL}$ water and $0.5 \mathrm{~mL}(1 \%, \mathrm{w} / \mathrm{v}) \mathrm{FeCl}_{3}$. After leaving the mix for $30 \mathrm{~min}$, the absorbance at $700 \mathrm{~nm}$ was registered. Data are presented as mg equivalent of the ascorbic acid standard per $g$ of extract (mg AAE/g DW). All OS extracts were assessed three times.

\section{Metal chelating activity (MCA)}

This test was applied on OS extracts by the previous modified method of Dinis and Madeira [24]. $60 \mu \mathrm{L}$ of $\mathrm{FeSO}_{4}$ $(0.2 \mathrm{mM})$ was mixed with $40 \mu \mathrm{L}$ of diluted samples. Then 80 $\mu \mathrm{L}$ of $2 \mathrm{mM}$ solution of ferrozine were added. The decrease of purple ferrozine- $\mathrm{Fe}^{2+}$ complex was assessed by determining absorbance at $550 \mathrm{~nm}$ (Fluostar Optima plate reader) after $10 \mathrm{~min}$ at room temperature. Using a calibration curve $(y=-0.0161 x+0.9112)$ with EDTA standard at the concentrations $10-75 \mu \mathrm{g} / \mathrm{mL}$, we calculated data as mg EDTA equivalent/g of dry mass (mg EDTA/g). All OS samples were analyzed in triplicate.

\section{The 3-(4,5-dimethylthiazol-2-yl)-2,5-diphe- nyl-2H-tetrazolium bromide assay (MTT)}

RAW 264.7 cells were seeded in 96-well plates for $48 \mathrm{~h}$ and activated or not with LPS at $10 \mu \mathrm{M}$, in the presence of different concentrations ( 50 to $300 \mu \mathrm{g} / \mathrm{mL}$ ) of OS extracts for $24 \mathrm{~h}$. To assess the cell viability, the cells were incubated with $0.5 \mathrm{mg} / \mathrm{mL}$ MTT solution for $3 \mathrm{~h}$ at $37{ }^{\circ} \mathrm{C}$ under $5 \%$ $\mathrm{CO}_{2}$. Then the supernatant was removed and the formazan crystals formed were dispended in $100 \mu \mathrm{L}$ of DMSO, and finally the absorbance was read using a micro plate (MRII, Dynex) at $595 \mathrm{~nm}$. All results were the average of 4 tests.

\section{Nitric oxide assay (NO)}

After incubation of the cells with or without LPS $(10 \mu \mathrm{M})$ in presence of different concentrations of OS for $24 \mathrm{~h}$, the culture medium was analyzed for nitrite by the Griess reaction. For this, $50 \mu \mathrm{L}$ of the Griess solution were added to $50 \mu \mathrm{L}$ of supernatant, the mixture was left for $15 \mathrm{~min}$ in the dark and then the absorbance at $550 \mathrm{~nm}$ was read using a microplate reader (MRII, Dynex). A calibration curve $(y=0.0105 x+0.1201)$ was performed under the same conditions with sodium nitrite.

\section{Measurement of reactive oxygene spices (ROS)}

The determination of ROS was carried out using the DCFH-DA probe sensitive to reactive oxygen species. In black 96-well plates, the cells were seeded according to the same method described in Sect. 2-7. After $6 \mathrm{~h}$, the culture medium was removed, the cells were washed with warm PBS and finally DCFH-DA $(5 \mu \mathrm{M})$ was added to cells for $30 \mathrm{~min}$ at $37^{\circ} \mathrm{C}$. Then the fluorescence intensity was read at wavelengths of $485 \mathrm{~nm}$ (excitation) and $520 \mathrm{~nm}$ (emission) using a flat reader (Fluostar Optima plate reader).

\section{Statistical analysis}

Statistical analyses were done with JMP software (Version 7.0, SAS) to find the response surfaces and to establish the model equation. The estimation of the mathematical models adjustment was obtained by the lack of fit and coefficient of determination $\left(\mathrm{R}^{2}\right)$. All comparisons were statistically assessed by ANOVA $(p<0.05)$ using STATISTICA 5.5.

\section{Results and discussion}

\section{Extraction using microwaves}

\section{Effects of single factors}

Particle size A separation of the OS powder was performed using three particle sizes $(\Phi \leq 500 \mu \mathrm{m}),(\Phi \leq 250 \mu \mathrm{m})$, and $(\Phi \leq 125 \mu \mathrm{m})$. A statistical difference was noticed between the TPC contents ranging from 2.27 to $3.25 \mathrm{mg}$ GAE/g (Table 1$)$. The particle size $(\Phi \leq 250 \mu \mathrm{m})$ was the best for maximum extraction of polyphenols. It is generally accepted that in a milled form, the plant material has a greater surface area of contact with the solvent [25]. This is explained by the fact that the solvent diffuses more easily inside the small particles, which enhances the extraction of polyphenol molecules thanks to the establishment of a larger contact surface with the solvent. In addition, the powder was not extremely fine which avoided the potential clogging phenomenon [26, 27].

Solvent type The results described in Table 1 revealed a significant influence $(p<0.05)$ of the solvent type on TPC extraction, which varied from 2.40 to $3.19 \mathrm{mg} \mathrm{GAE} / \mathrm{g}$. Etha- 
nol was the best extraction solvent with $3.19 \mathrm{mg} \mathrm{GAE} / \mathrm{g}$. This result is similar to those find by Bruno et al. [28] in a work conducted on olive pomace extracts. This variation in the extracted content resulted from the difference in polarity existing between the used solvents [29]. This was in accordance with other studies [30].

Ethanol concentration The statistical study $(p<0.05)$ showed a notable statistical difference between the TPC obtained by the different concentrations of ethanol used, ranging from 2.44 to $3.43 \mathrm{mg} \mathrm{GAE} / \mathrm{g}$, following a parabolic curve from 20 to $100 \%$ (Table 1). The lowest quantity of TPC was obtained when the extraction medium was entirely composed of $100 \%$ ethanol. The inclusion of distilled water in the ethanol solvent seemed to be highly effective for the recovery of polyphenols, because it ensured both the retrieval of antioxidants and the preservation of their potential activity [30]. We designated ethanol with concentration of $40 \%$ as our choice for further determinations.

Microwave power The microwave power contributed to an increase in TPC content from 2.83 to $3.60 \mathrm{mg}$ GAE/g between power levels from 100 to $700 \mathrm{~W}$ (Table 1). However, a significant reduction of TPC was registered beyond $800 \mathrm{~W}$, with the lowest amount observed at $1000 \mathrm{~W}$ ( $2.96 \mathrm{mg} \mathrm{GAE} / \mathrm{g}$ ). This may be related to thermal degradation of these compounds beyond $800 \mathrm{~W}$.

Based on these preliminary tests, the powers of 500, 700 and $900 \mathrm{~W}$ had been assigned to the three lower, middle and upper levels of the experimental design.

Irradiation time The time during which the solvent and the plant material were in contact can influence the gradual release of solutes from the plant matrix to the solvent, and thus the effectiveness of extraction. By setting solvent concentration at $40 \%$ ethanol (v/v), $700 \mathrm{~W}$ power level of microwave and 1:20 g/mL solid-to-liquid ratio, the TPC was evaluated at different procedural times ranging from 30 to $150 \mathrm{~s}$. The results indicated that the TPC recovery rose with the increase of MAE irradiation time with a maximum of $3.58 \mathrm{mg} \mathrm{GAE} / \mathrm{g}$ at $60 \mathrm{~s}$ followed by a decrease at $90 \mathrm{~s}$, with a minimum of $2.85 \mathrm{mg} \mathrm{GAE} / \mathrm{g}$ at $150 \mathrm{~s}$ (Table 1). Based on these results, an extraction time equal to $60 \mathrm{~s}$ was selected for its subsequent application in the optimization plan by RSM.

Solid-to-liquid ratio The TPC of the OS extracts increased inversely to the solid/liquid ratio during extraction (Table 1) and was maximum at a solid/liquid ratio of $1: 60(\mathrm{~g} / \mathrm{mL})$. Both ratios 1:40-1:80 (w/v) were employed during MAE optimization process. Al-Farsi and Lee [31] reported results of the same magnitude about the solid/liquid ratio influence on the TPC extraction from date stones.

\section{MAE setting optimization}

\section{Modeling and fitting the model}

Four factors $X_{1}$ (ethanol concentration), $X_{2}$ (microwave power), $\mathrm{X}_{3}$ (irradiation time) and $\mathrm{X}_{4}$ (solid-to-liquid ratio) at three levels $(-1,0$ and 1$)$ were applied to maximize the TPC recovery from OS cv Ayemele powder. It was shown that all linear parameters $\mathrm{X}_{1}, \mathrm{X}_{2}, \mathrm{X}_{3}$, and $\mathrm{X}_{4}$ and their quadratic parameters, except for the parameter $\mathrm{X}_{2}$, were highly significant at the level $p<0.0001$ (Table 2). Additionally, all the synergy parameters were statistically significant at the level $p<0.0001$. The BBD plan is a classical second-order model, which is deliberately simplified by eliminating the effects of interactions considered insignificant in the analysis, which makes it easier to manipulate reduced expression while maintaining a nearly similar quality of fit [32].

The ultimate equation (Eq. 1) was as follows:

$$
\begin{aligned}
Y(T P C)= & 4.98-0.29 X_{1}-0.16 X_{2}+0.45 X_{3}+0.36 X_{4} \\
& +0.24 X_{1} X_{2}+0.45 X_{1} X_{3}-0.23 X_{1} X_{4}+0.20 X_{2} X_{4} \\
& +0.47 X_{3} X_{4}-0.34 X_{1}^{2}-0.33 X_{2}^{2}-0.13 X_{4}^{2}
\end{aligned}
$$

The overall adjustment efficiency was expressed by the correlation coefficient $R^{2}$ [33]. In this study, it has been noted a $\mathrm{R}^{2}$ value about 0.98 , so that only $0.02 \%$ of the variations were not explained by the model. In addition, the determination adjusted coefficient was high $\left(\mathrm{R}^{2}\right.$ adjusted $=0.95$ ), which confirmed the high significance of the model. The Lack of Fit F-value of 0.64 means was insignificant compared to pure error $(p>0.05)$, confirming the validity of the model. The obtained data affirmed that the investigated model could be extrapolated to predict TPC of all OS extracts.

\section{Response surfaces analysis}

Figure 1 shows all the possible interactive effects obtained by Eq. (1). We note that all parameters had a highly notable impact on TPC extraction from the studied powder. As shown in Table 2, there was a dependence between the recovery rate of polyphenols and the ethanol concentration; this was confirmed by the great significance of its quadratic and linear effects $(p<0.0001)$. Marginal variations in the composition of the solvent may cause significant impacts on the quality and quantity of the extracted compounds [34]. Indeed, various studies have indicated the interest of the solvent concentration compared to other factors [33, 35-37]. An extraction system with an extended time and a high microwave power generates a higher temperature, and this synergy of time and temperature can make the phenolic 
Table 2 Analysis of mean square deviation of the quadratic model terms applied to the experimental values of total phenolic yields obtained with microwave assisted extraction

\begin{tabular}{|c|c|c|c|c|c|}
\hline Source & Sum of squares & df & F-value & $\mathrm{p}$-value Prob $>\mathrm{F}$ & \\
\hline Model & 9.0786 & 14 & 37.6669 & $<0.0001$ & Significant \\
\hline $\mathrm{X}_{1}$-ethanol & 1.0520 & 1 & 61.0020 & $<0.0001$ & \\
\hline $\mathrm{X}_{2}$-power & 0.3333 & 1 & 19.3619 & 0.0009 & \\
\hline $\mathrm{X}_{3}$-time & 2.4570 & 1 & 142.7207 & $<0.0001$ & \\
\hline $\mathrm{X}_{4}$-ratio & 1.5552 & 1 & 90.3347 & $<0.0001$ & \\
\hline $\mathrm{X}_{1} \mathrm{X}_{2}$ & 0.2352 & 1 & 13.6632 & 0.0031 & \\
\hline$X_{1} X_{3}$ & 0.0090 & 1 & 0.5242 & 0.4829 & \\
\hline $\mathrm{X}_{2} \mathrm{X}_{3}$ & 0.8281 & 1 & 48.1007 & $<0.0001$ & \\
\hline $\mathrm{X}_{1} \mathrm{X}_{4}$ & 0.2162 & 1 & 12.5596 & 0.0040 & \\
\hline $\mathrm{X}_{2} \mathrm{X}_{4}$ & 0.1640 & 1 & 9.5275 & 0.0094 & \\
\hline $\mathrm{X}_{3} \mathrm{X}_{4}$ & 0.8836 & 1 & 51.3244 & $<0.0001$ & \\
\hline $\mathrm{X}_{1}^{2}$ & 0.6424 & 1 & 37.3194 & $<0.0001$ & \\
\hline $\mathrm{X}_{2}^{2}$ & 0.6105 & 1 & 35.4615 & $<0.0001$ & \\
\hline $\mathrm{X}_{3}^{2}$ & 0.0344 & 1 & 2.0034 & 0.1824 & \\
\hline $\mathrm{X}_{4}^{2}$ & 0.0948 & 1 & 5.5074 & 0.0369 & \\
\hline Residual $\mathrm{R}^{2}$ & 0.2065 & 12 & & 0.98 & \\
\hline Adjusted $\mathrm{R}^{2}$ & & & & 0.95 & \\
\hline Lack of fit & 0.1577 & 10 & 0.6467 & 0.7401 & Not significant \\
\hline Pure error & 0.0488 & 2 & & & \\
\hline Cor total & 9.2852 & 26 & & & \\
\hline
\end{tabular}

$d f$ degrees of freedom compounds more soluble by decreasing the viscosity of the solvent used in the extraction [38].

The resulted optimal conditions were: irradiation time $40 \mathrm{~s}$, extraction power $500 \mathrm{~W}$, solid-to-solvent ratio 1:65 and $22 \%$ in terms of ethanol concentration, with an anticipated TPC yield of $5.08 \mathrm{mg} \mathrm{GAE} / \mathrm{g}$. Under these optimal conditions, the TPC result obtained experimentally was $5.14 \pm 0.16 \mathrm{mg} \mathrm{GAE} / \mathrm{g}$, not far from the value assumed by the model and confirming the results of the single-factor trials. The predicted amounts by the model and those initiated by these results were in harmony confirming to be not statistically different $(p>0.05)$. That confirms that the model was adequate for reflecting the expected optimization of TPC from OS.

\section{Conventional solvent extraction (CSE)}

\section{Single parameters test analysis}

Table 3 shows the single factor experiments results carried out for preliminary optimization of CSE. Four factors $\mathrm{X}_{1}$ solvent concentration, $\mathrm{X}_{2}$ extraction temperature, $\mathrm{X}_{3}$ extraction time, $X_{4}$ solid to liquid ratio were investigated. The statistical analysis $(p>0.05)$ showed a significant variance between the TPC contents extracted by different concentrations of ethanol, ranging from 1.81 to $2.41 \mathrm{mg} \mathrm{GAE} / \mathrm{g}$. We designated the ethanol concentration varying from 20 and $60 \%$ for the RSM trials. The extraction time was another main parameter in the extraction procedure of TPC which can vary from a few minutes to $24 \mathrm{~h}[39,40]$. An extend contact time does not always ameliorate the power of the extraction as it can promote the oxidation of phenolic compounds [41].

The statistical study $(p>0.05)$ revealed a significant difference between the polyphenol content extracted at different extraction times, which varied from 2.52 to $3.13 \mathrm{mg}$ GAE/g. Thus, the extraction time giving a maximum of TPC should be in the neighborhood of $30 \mathrm{~min}$. Concerning the temperature, the increase in temperature improved the extraction of polyphenols, rendering cell membranes more penetrable, and enhancing the diffusion coefficient of the compounds to be kept and thus increasing their solubility. However, excessive temperatures can cause degradation of phenolic compounds, or may cause a decrease in extraction selectivity, which limits extraction temperatures to a certain threshold [42].

According to the statistical study, we noticed a notable variation $(p>0.05)$ between the extracted TPC, ranging from 1.93 to $2.95 \mathrm{mg} \mathrm{GAE} / \mathrm{g}$, with a temperature close to $70{ }^{\circ} \mathrm{C}$ for optimal extraction. Our results were homogenous with other works on olive pomace [43].

\section{Optimization by RSM}

Analysis of the regression model and regression coefficients is summarized in Table 4. It is noticed that the value of $R^{2}$ is 

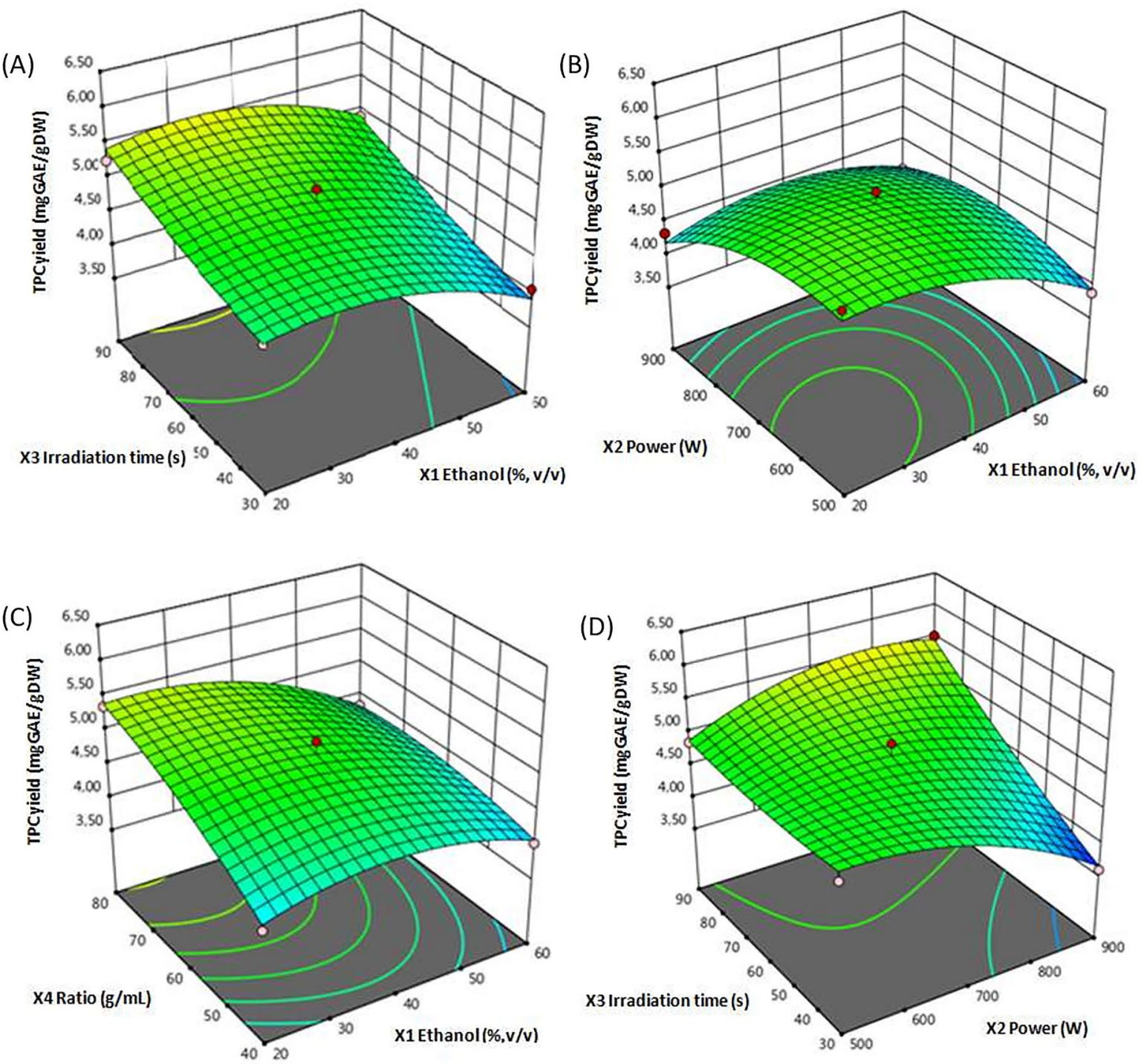

(E)
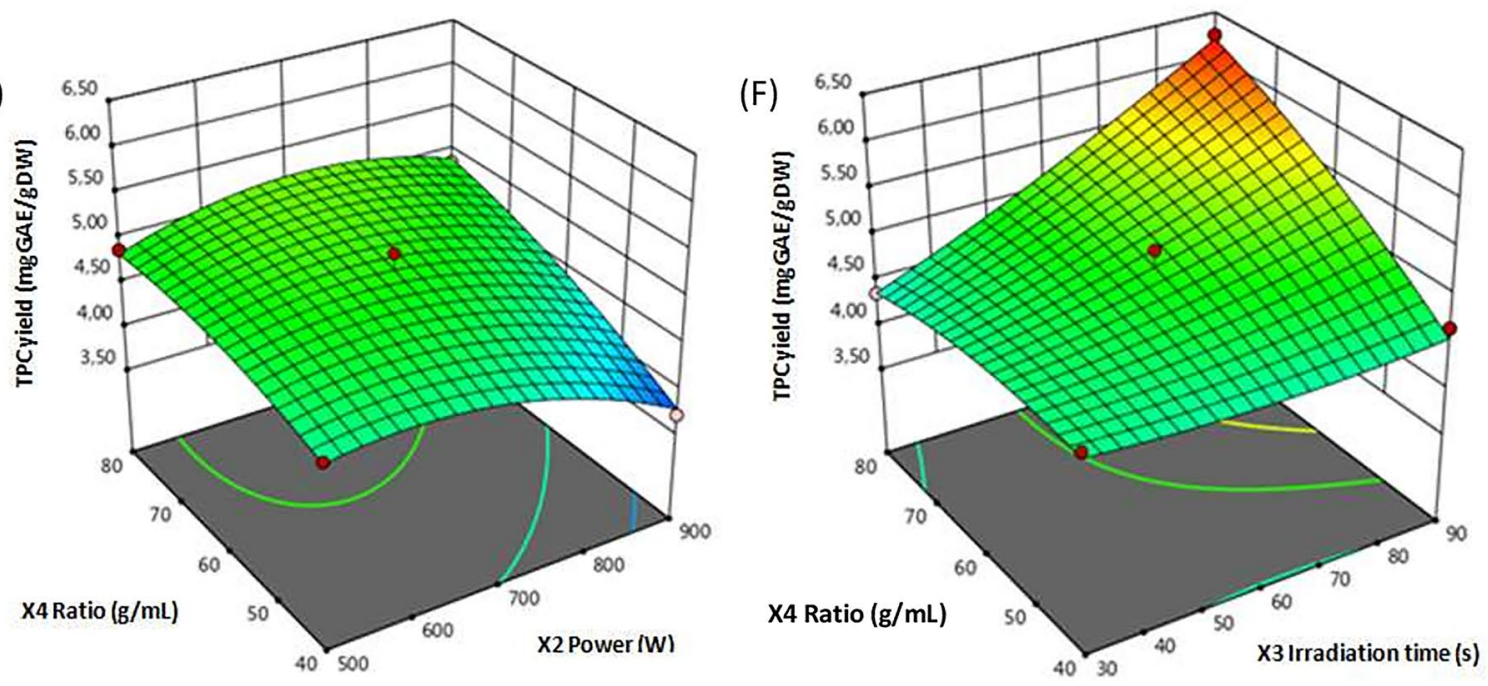
4Fig. 1 Response surface analysis of the effect of microwave extraction on TPC yield of olive stones extracts. A Irradiation time and ethanol concentration, $\mathbf{B}$ microwave power and ethanol concentration, C solid-to-liquid ratio and ethanol concentration, D Irradiation time and microwave power, $\mathbf{E}$ solid-to-liquid ratio and microwave power, $\mathbf{F}$ solid-to-liquid ratio and Irradiation time

0.96 , which means that only $0.04 \%$ of the variations are not explained by the model. In addition, the value of the adjusted coefficient of determination is high (adjusted $\mathrm{R}^{2}=0.90$ ), which confirms the high significance of the model.

The results of the present study show that the factor with higher influence on the extraction of polyphenols is the concentration of the solvent $\left(\mathrm{X}_{1}\right)$, temperature $\left(\mathrm{X}_{2}\right)$ and the extraction time $\left(\mathrm{X}_{3}\right)$ and ratio $\left(\mathrm{X}_{4}\right)$. For the interaction effect, the data indicate that the ratio-temperature interactions $\left(\mathrm{X}_{1}-\mathrm{X}_{3}\right)$ and $\left(\mathrm{X}_{2}-\mathrm{X}_{4}\right)$ are the most significant on the extraction of polyphenols with a probability $\mathrm{p}=0.0001$.

Neglecting the non-significant terms $(p>0.01)$, the final predictive equation for CSE was (Eq. (2)):

$$
\begin{aligned}
Y(T P C)= & 3.28-0.21 X_{1}+0.13 X_{2}+0.14 X_{3}+0.54 X_{1} X_{3} \\
& +0.47 X_{2} X_{3}+0.35 X_{1} X_{4}+0.80 X_{2} X_{4}-0.56 X_{1}^{2}-0.25 X_{2}^{2}
\end{aligned}
$$

To follow the influences of operational parameters and to control optimal levels of the variables, three-dimensional surface plots were constructed according to Eq. (2) as for MAE (Fig. 2). Our determinations revealed that the factor which mostly influenced the TPC recovery was the solvent concentration. According to Spigno, Tramelli [44], alcoholdistilled water mixtures gave better extraction efficiency of polyphenols compared to single-solvent systems. As stated in the results found by Telli and Mahboub [45], the extraction time, if combined with the correct type of solvent, influences considerably the amount of recovered polyphenols, so the prolongation in the extraction time importantly increased the extraction power.

When rising the temperature, as already mentioned, the solvent viscosity was lower, so the solution solubility was increased. Heat also facilitates extraction because it raises cell wall permeability. D'Alessandro, Vauchel $[46,47]$ found that temperature was the parameter having the greater influence on the modification of TPC content. From the presented model the optimal conditions of CSE were: a solid/liquid ratio of $1: 60(\mathrm{w} / \mathrm{v}), 33.4 \%$ ethanol concentration, for a procedure time of $24 \mathrm{~min}$ at $71{ }^{\circ} \mathrm{C}$ and with a predicted yield of $4.65 \mathrm{mg} \mathrm{GAE} / \mathrm{g}$. CSE was carried out under these conditions giving a real recovery of $4.54 \pm 0.48 \mathrm{mg} \mathrm{GAE} / \mathrm{g}$.

\section{MAE and CSE comparison}

The alternative technology MAE was compared with CSE considering the values of TPC, total flavonoid and antioxidant activities (DPPH, ORAC, PFRAP and ICA) obtained for the OS Ayemel optimized extract (Table 5). The CSE presented a polyphenol yield of $4.54 \pm 0.48 \mathrm{mg}$ GAE/g DW which was statistically different $(p>0.05)$ compared with the MAE yield of $5.14 \pm 0.16 \mathrm{mg} \mathrm{GAE} / \mathrm{g}$ DW. The same tendency was noted with the TFC between MAE and CSE ( 0.21 and $0.18 \mathrm{mg} \mathrm{QE} / \mathrm{g}$, respectively). The use of microwaves in the polyphenol extraction from olive stones increased significantly the antioxidant activities $(p<0.05)$ compared to traditional extraction. With the regard to the applied solvent, ethanol was the most powerful one, giving the best extraction productivity, while acetone gave the lowest yield in extracting polyphenols by both methods.

For MAE and maceration method, the highest phenolic quantity was obtained from ethanol extract of Ayemel variety after $30 \mathrm{~s}$ and $24 \mathrm{~min}$, respectively. The statistical anaysis revealed that the designated method had a considerable effect on the extraction of phenolic compounds $(p<0.05)$. Comparing the two developed procedures, MAE seemed to give higher extraction effectiveness with reduced extraction time, resulting as an appropriate alternative for maceration method. Interaction of microwave with solvent molecules causes an abrupt increase in temperature and pressure inside the plant tissues, which facilitates the subsequent break of cellular wall and the output of active compounds into the solvent [48].

This notable capacity of MAE to trigger strong phenolic yield in comparison to maceration method has been already studied (Rafiee et al. 2011; Sanghi and Kannamkumarath 2004). Furthermore, other studies reported that MAE can significantly reduce extraction time compared to conventional extraction methods [49,50]. The polyphenols extraction from OS by microwave seemed to be better than maceration, giving extracts with a higher concentration of phenolic compounds.

\section{Comparison of six olive stones varieties after phe- nolic extraction by MAE}

Total phenolic and flavonoid contents as well as antioxidant activity from OS of various algerian native varieties (Ayemel, Achemlale, Azeradj, Agraraz, Atefah, Azeboudj) were studied after phenolic extraction with MAE optimal conditions (Table 5). The statistical comparison $(p>0.05)$ revealed notable differences between TPC of the six varieties ranging from 5.14 to $7.23 \mathrm{mg} \mathrm{GAE} / \mathrm{g}$. Results showed that Achemlale olive stones had the highest amount of phenolic compounds, while Ayemel was the poorest one. These results are in accordance with those reported by Elbir and Amhoud [51] in a work conducted on 2 samples of Haouzia and Picholine olive stones harvested in Maroco. A similar profile was observed for flavonoids composition of the different varieties of OS, with 


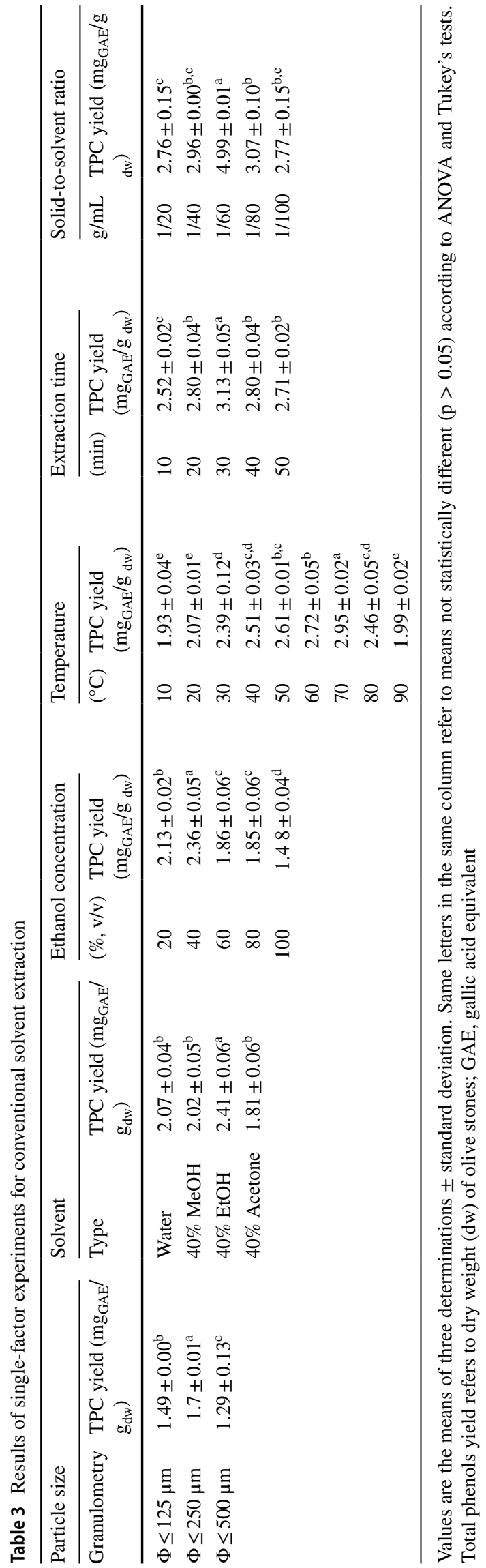

Achemlale variety being the richest one $(0.36 \mathrm{mg}$ QE/g). This result was close to those reported by Zaidi et al. [52] in olive pomace with content of $0.24 \mathrm{mg} \mathrm{EQ} / \mathrm{g}$, but higher from that reported by Hannachi and Elfalleh [53] with $0.13 \mathrm{mg} \mathrm{EQ} / \mathrm{g}$ of OS. Previous works suggested that this variation on polyphenol and flavonoid contents was the result of several factors such as growing area and climatic conditions [54-56].

Polyphenols and flavonoids are primordial molecules having preventive role in plants against free radicals and their presence has been reported by many authors in olive and olive pomace $[57,58]$. To evaluate the antioxidant capacity of OS extracts of the six varieties, we carried out several assays: ORAC, DPPH, ABTS, ICA and PFRAP. For DPPH and ORAC assays, extracts of the six varieties of OS exhibited significant different scavenging activity $(p>0.05)$. The varieties with the most important antioxidant activity were Atefah, Achemlale, and Azeboudj, with ORAC values of $218.04,201.35$ and $195.24 \mathrm{mg}$ of TE/g respectively. In the literature, OS extracts displayed equivalent values [53].

Bruno et al. [59] found higher DPPH values equivalent to $189.71 \mu \mathrm{mol}$ Trolox/g in a comparative study between drupes of varieties grown in Italy. The reduction of ferric chloride was employed as an indicator of electron donor activity, which is a relevant process for the antioxidant action of polyphenols. So the antioxidant capacity of the OS extracts was evaluated with PFRAP and ICA assays. Achemlale presented a PFRAP value of $34.42 \mathrm{mg}$ EAA/g and ICA value of $8.14 \mathrm{mg}$ of EDTA/g. Results showed that the varieties having a higher DPPH and ORAC activities had similarly a greater capacity with the PFRAP and MCA tests. Different from our findings, according to Nadour [60], olive pulp had a ferric chloride reduction capacity of $24 \mathrm{mg}$ equivalent of vitamin $E$ per gram of product. Thus, dissemblance between the data reported in the literature and our results was justifiable. Indeed, several works have shown that antifree radical power can be influenced by the extraction procedure, the solvent (its nature and concentration), the duration, the temperature, and the variety [61, 62]. Dissimilarities can also be ascribed to the source of the matrix, the TPC extraction procedure, and the collection season [58], as well as to geographic origin or climatic factors. About Chemlale, a famous cultivated variety in the Mediterranean region for the quality of its oil, previous works have been done even on the olive stones $[53,63]$ which confirmed our results concerning the highest polyphenol content and antioxidant activity of this cultivar. Regarding the never previously studied varieties Atefah and Azeboudj, which is an oleaster, we found that they have a great antioxidant power. Little information has been reported about phytochemicals present in oleaster stone and about the other varieties of olive stone cited in the present investigation like Ayemel and Agraraz. The data presented here offers better information on the chemical 
Table 4 Analysis of mean square deviation of the quadratic model terms applied to the experimental values of total phenolic yields obtained with conventional solvent extraction

\begin{tabular}{|c|c|c|c|c|c|}
\hline Source & Sum of squares & $\mathrm{df}$ & F-value & p-value Prob $>F$ & \\
\hline Model & 8.4086 & 14 & 18.8650 & $<0.0001$ & Significant \\
\hline $\mathrm{X}_{1}$-ethanol & 0.5504 & 1 & 17.0145 & 0.0014 & \\
\hline $\mathrm{X}_{2}$-Temperature & 0.2296 & 1 & 7.0986 & 0.0260 & \\
\hline $\mathrm{X}_{3}$-time & 0.2380 & 1 & 7.3574 & 0.0189 & \\
\hline $\mathrm{X}_{4}$-ratio & 0.1240 & 1 & 3.8342 & 0.0739 & \\
\hline $\mathrm{X}_{1} \mathrm{X}_{2}$ & 0.0144 & 1 & 0.4451 & 0.5173 & \\
\hline$X_{1} X_{3}$ & 1.1664 & 1 & 36.0564 & $<0.0001$ & \\
\hline $\mathrm{X}_{2} \mathrm{X}_{3}$ & 0.9120 & 1 & 28.1930 & 0.0002 & \\
\hline $\mathrm{X}_{1} \mathrm{X}_{4}$ & 0.4970 & 1 & 15.3643 & 0.0020 & \\
\hline $\mathrm{X}_{2} \mathrm{X}_{4}$ & 2.5760 & 1 & 79.6315 & $<0.0001$ & \\
\hline $\mathrm{X}_{3} \mathrm{X}_{4}$ & 0.0289 & 1 & 0.8934 & 0.3632 & \\
\hline $\mathrm{X}_{1}^{2}$ & 1.7176 & 1 & 53.0965 & $<0.0001$ & \\
\hline $\mathrm{X}_{2}{ }^{2}$ & 0.3366 & 1 & 10.4075 & 0.0073 & \\
\hline $\mathrm{X}_{3}^{2}$ & 0.0003 & 1 & 0.0093 & 0.9249 & \\
\hline $\mathrm{X}_{4}^{2}$ & 0.4070 & 1 & 12.5817 & 0.0040 & \\
\hline Residual & 0.0331 & 12 & & & \\
\hline $\mathrm{R}^{2}$ & & & & 0.96 & \\
\hline Adjusted $\mathrm{R}^{2}$ & & & & 0.90 & \\
\hline Lack of fit & 0.3083 & 10 & 0.7729 & 0.6836 & Not significant \\
\hline Pure error & 0.0798 & 2 & & & \\
\hline Cor total & 8.7968 & 26 & & & \\
\hline
\end{tabular}

$d f$ degrees of freedom

capacities of olive stones as innovative natural constituents to be tested in food industry or pharmaceutical field.

\section{Anti-inflammatory activity in RAW 264.7 mac- rophage cells}

\section{Cell viability}

The cytotoxic effect on RAW 264.7 of the studied OS extracts (Achemlale, Azeboudj, Atefah, Agraraz, Azeradj, and Ayemel) was assessed by the reduction of MTT to formazan by living cells. The results were compared to the negative control (RAW cells 264.7+LPS). We tested the cytotoxic potential of the extracts up to a concentration of $300 \mu \mathrm{M}$. The results showed that Azeboudj and Ayemele OS extracts were toxic from the first concentration tested $(50 \mu \mathrm{M})$, therefore they were no longer taken in consideration for the next tests. The other OS extracts, Achemlale, Atefah, Agraraz, and Azeradj, did not show cytotoxic effect on cell viability, even at the highest tested concentration.

\section{Nitric oxide (NO) and reactive oxygen species (ROS) produc- tion}

In our experiment, LPS, the major constituent of the bacteria outer membrane, is used to trigger activation of inflammatory mechanisms in RAW 264.7 cells. This reaction releases chemical warning signals such as nitric oxide, cytokines and ROS. In order to detect the effect of OS extracts of Achemlale, Atefah, Agraraz, and Azeradj varieties on the production of nitrite oxide, we assessed the level of nitrite in the culture medium of macrophages. Results are presented in Fig. 3. In comparison with the control, the treatment of the cells with extracts of OS at concentrations between 50 to $300 \mu \mathrm{M}$ has shown a remarkable reduction of NO production according to the dose, after $24 \mathrm{~h}$. Extracts of the varieties Atefah, Achemlale, and Agraraz gave the best protective effects with an $\mathrm{IC}_{50}$ value of $234.2 \pm 11.5,292.9 \pm 7.6$, and $293.8 \pm 1.5 \mu \mathrm{M}$ of $\mathrm{OS}$ extract, respectively. The extract of Azeradj was less effective and we could not calculate its $\mathrm{IC}_{50}$. We also investigated the ROS production in LPS-induced RAW 24.7 cells by using the DCFH-DA method (Fig. 3). The results revealed a decrease in ROS production for OS extracts of varieties of Atefah, Achemlale, and Agraraz at concentrations ranging from 50 to $300 \mu \mathrm{M}$. The Atefah extract was the most effective on ROS production, since at $250 \mu \mathrm{M}$ a reduction of $50 \%$ in ROS production compared to the control could be observed. Extracts may have a protective role against lipoprotein oxidation and in this way they can contribute to the prevention of diseases including an antiinflammatory reaction, such as cardiovascular diseases. Lot of studies have already considered the possibility of using olive stones in several fields such as cosmetics, dietary animal supplementation and metal biosorbent [64]. 
(A)
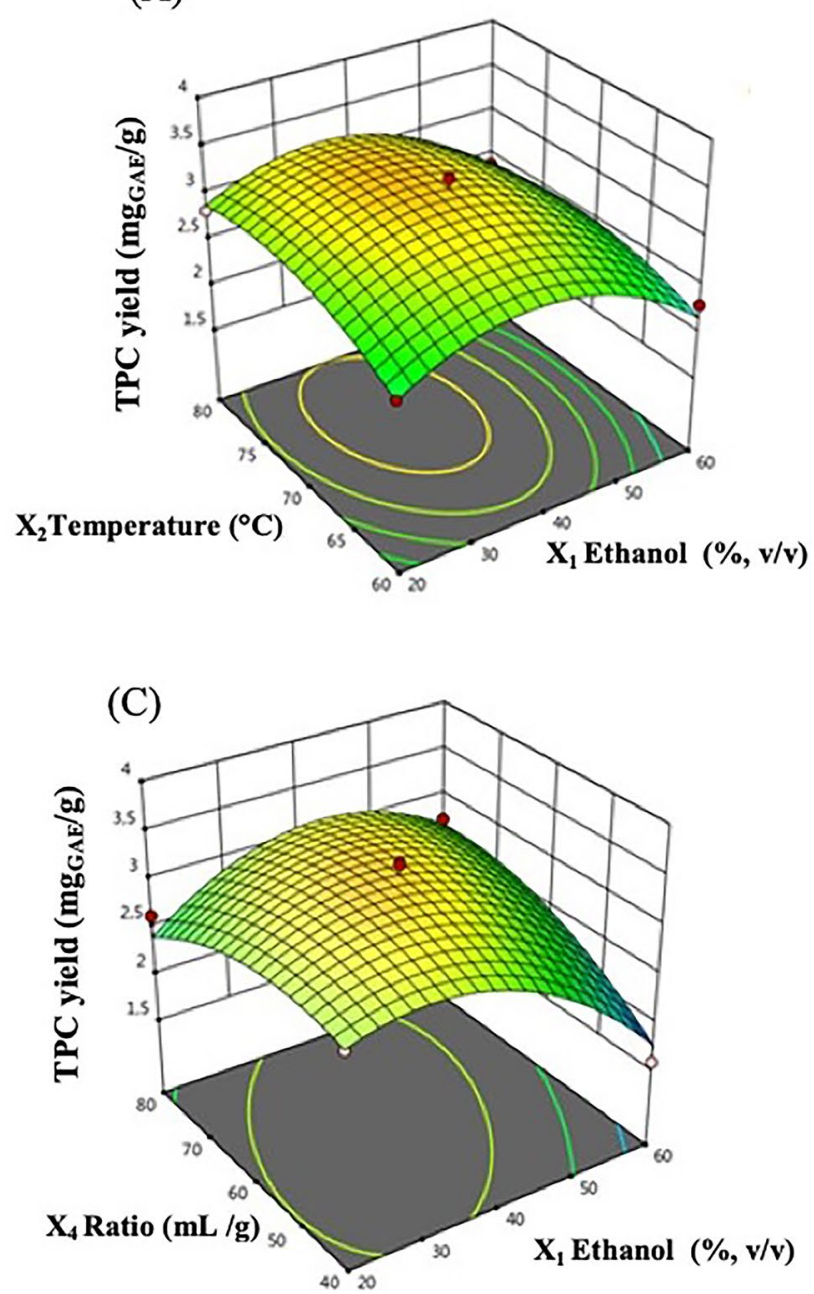

(E)

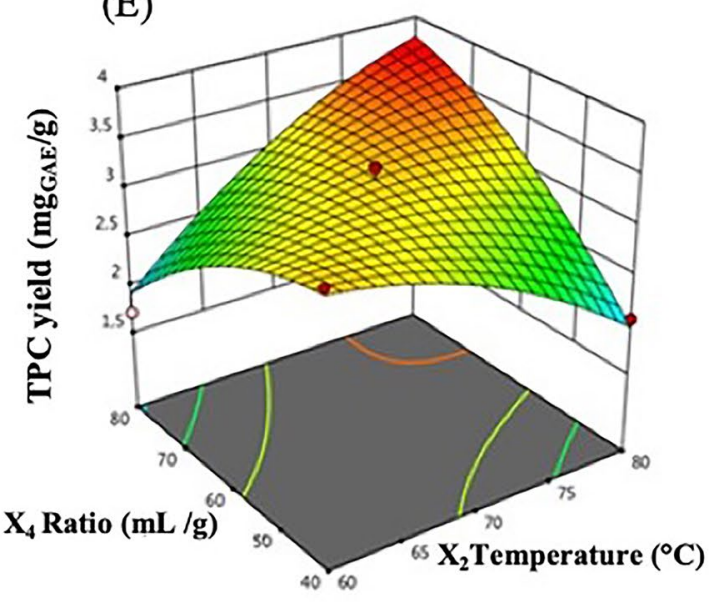

Fig. 2 Response surface analysis of the effect of conventional solvent extraction on TPC yield of olive stones extracts. A Temperature and ethanol concentration, B time and ethanol concentration, $\mathbf{C}$ solid-

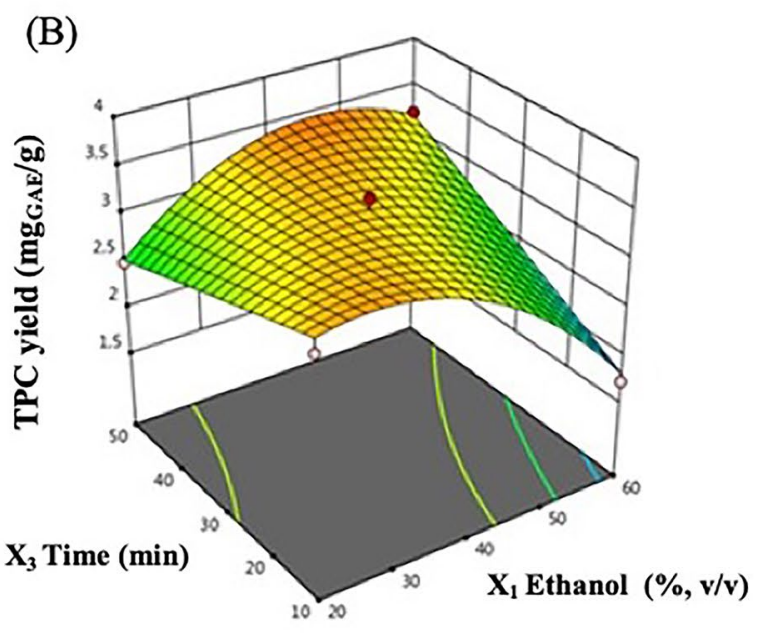

(D)
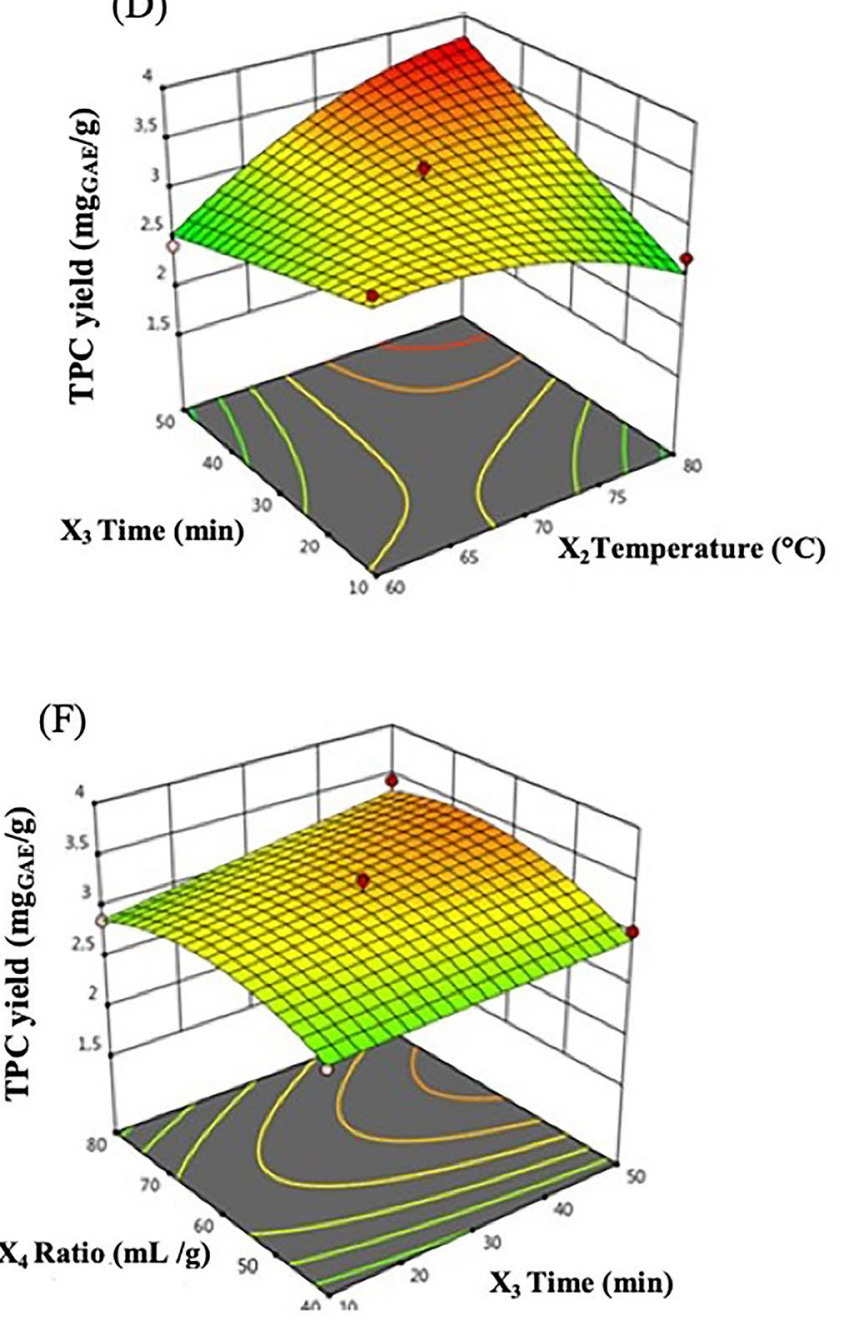

to-liquid ratio and ethanol concentration, $\mathbf{D}$ time and temperature, $\mathbf{E}$ solid-to-liquid ratio and temperature, $\mathbf{F}$ solid-to-liquid ratio and time 
Table 5 Comparison between the two optimized methods: CSE and MAE and six varieties of olive stones extracted by MAE best conditions in term of TPC, TFC and total antioxidant activity

\begin{tabular}{lllllll}
\hline Extraction method & TPC $(\mathrm{mg}$ GAE/g) & TFC $(\mathrm{mg}$ QE/g) & $\begin{array}{l}\text { DPPH }(\mathrm{mg} \text { of } \\
\text { TE/g) }\end{array}$ & $\begin{array}{l}\text { ORAC }(\mathrm{mg} \text { of } \\
\text { TE/g) }\end{array}$ & $\begin{array}{l}\text { PFRAP (mg } \\
\text { EAA/g) }\end{array}$ & $\begin{array}{l}\text { ICA (mg of EDTA/g) } \\
\text { CSE }\end{array}$ \\
\hline MAE & $4.54 \pm 0.48^{\mathrm{b}}$ & $0.06 \pm 0.09^{\mathrm{b}}$ & $8.73 \pm 0.18^{\mathrm{b}}$ & $148.92 \pm 8.24^{\mathrm{b}}$ & $20.6 \pm 1.0^{\mathrm{a}}$ & $2.38 \pm 0.41^{\mathrm{b}}$ \\
Ayemel & $5.14 \pm 0.16^{\mathrm{a}}$ & $0.09 \pm 0.01^{\mathrm{a}}$ & $9.93 \pm 0.28^{\mathrm{a}}$ & $137.53 \pm 11.3^{\mathrm{a}}$ & $20.7 \pm 1.3^{\mathrm{a}}$ & $4.09 \pm 0.49^{\mathrm{a}}$ \\
Achemlale & $5.14 \pm 0.16^{\mathrm{e}}$ & $0.09 \pm 0.01^{\mathrm{d}}$ & $9.93 \pm 0.28^{\mathrm{e}}$ & $148.92 \pm 8.24^{\mathrm{b}}$ & $20.7 \pm 1.32^{\mathrm{c}}$ & $4.09 \pm 0.49^{\mathrm{c}}$ \\
Azeradj & $7.23 \pm 0.08^{\mathrm{a}}$ & $0.36 \pm 0.01^{\mathrm{a}}$ & $23.72 \pm 0.37^{\mathrm{d}}$ & $201.35 \pm 15.04^{\mathrm{a}}$ & $34.42 \pm 1.36^{\mathrm{a}}$ & $8.14 \pm 0.41^{\mathrm{a}}$ \\
Agraraz & $5.35 \pm 0.05^{\mathrm{e}}$ & $0.09 \pm 0.01^{\mathrm{d}}$ & $12.42 \pm 1.47^{\mathrm{a}}$ & $157.40 \pm 12.71^{\mathrm{b}}$ & $21.06 \pm 1.11^{\mathrm{c}}$ & $6.53 \pm 0.30^{\mathrm{b}}$ \\
Atefah & $5.63 \pm 0.08^{\mathrm{d}}$ & $0.15 \pm 0.01^{\mathrm{c}}$ & $21.13 \pm 1.15^{\mathrm{c}}$ & $195.24 \pm 18.14^{\mathrm{a}}$ & $28.56 \pm 1.89^{\mathrm{b}}$ & $4.85 \pm 0.32^{\mathrm{c}}$ \\
Azeboudj & $6.04 \pm 0.15^{\mathrm{c}}$ & $0.16 \pm 0.01^{\mathrm{c}}$ & $32.87 \pm 1.31^{\mathrm{a}}$ & $218.04 \pm 12.58^{\mathrm{a}}$ & $30.19 \pm 2.14^{\mathrm{a}, \mathrm{b}}$ & $6.85 \pm 0.95^{\mathrm{b}}$ \\
\hline
\end{tabular}

Values are the means of three determinations \pm standard deviation. Same letters in the same column refer to means not statistically different ( $\mathrm{p}>$ $0.05)$ according to ANOVA and Tukey's tests

$T E$ trolox equivalent, $E A A$ ascorbic acid equivalent, GAE gallic acid equivalent, $E D T A$ ethylene diamine tetraacetic acid equivalent

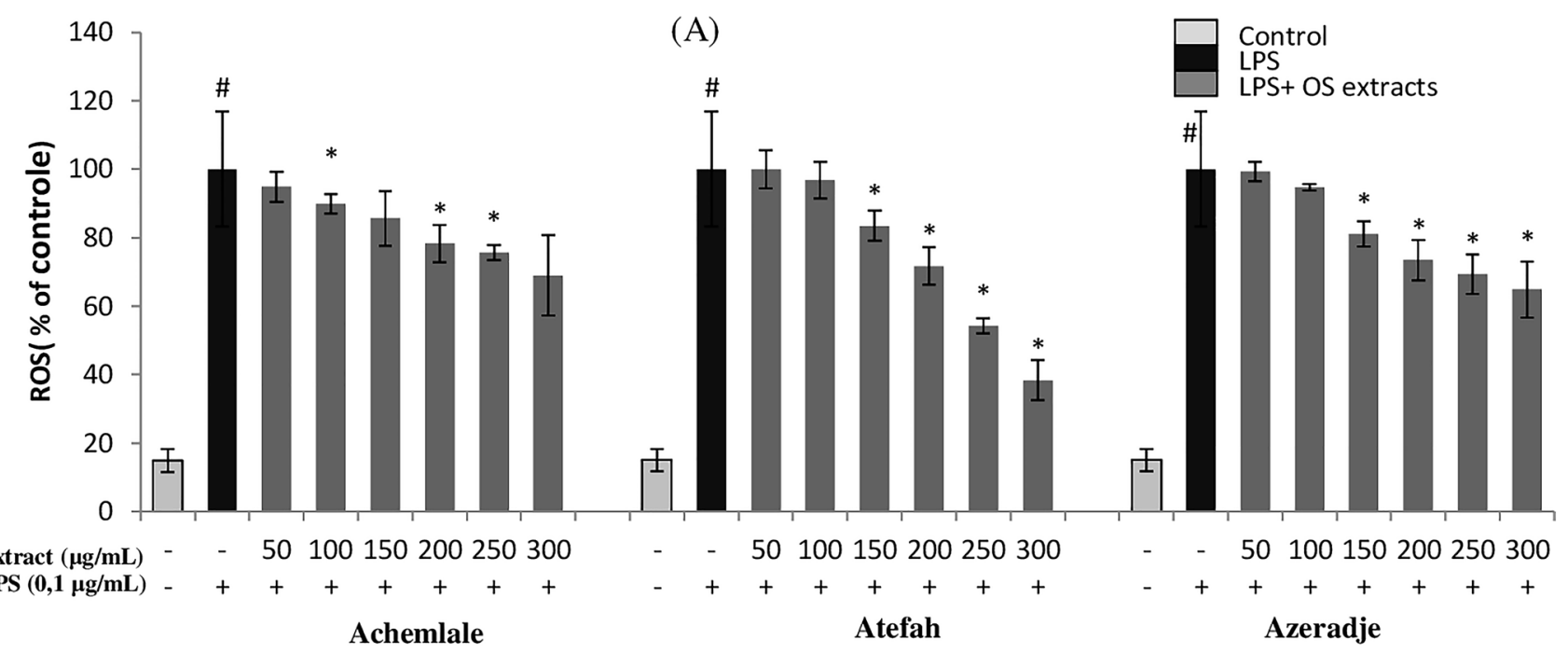

(B)

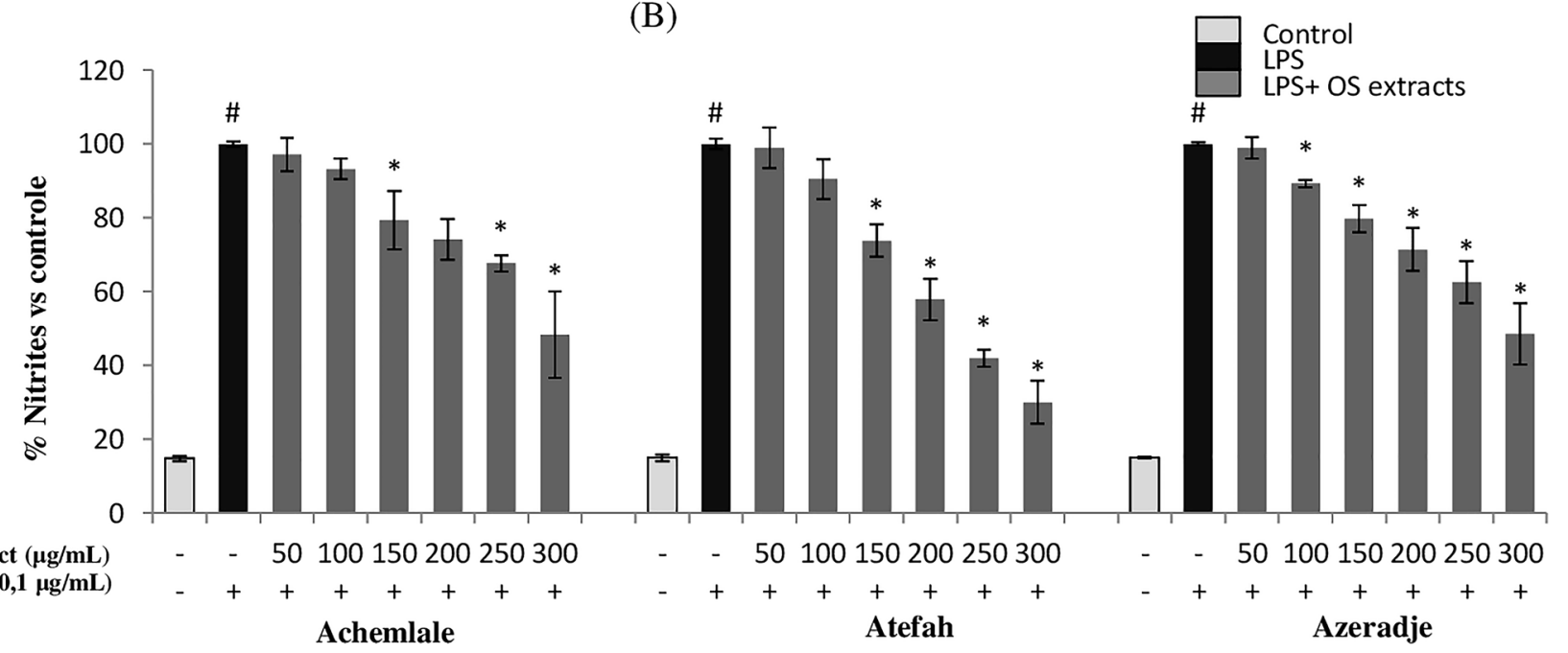

Fig. 3 A Reactive oxygen species (ROS) production of OS extracts in RAW 264.7 cells. Production of intracellular ROS was measured by the fluorescent probe DCFH-DA. B Nitric oxide (NO) and OS extracts in RAW264.7 cells the culture medium was analyzed for nitrite by the Griess reaction, after incubation of the cells with or without LPS $(10 \mu \mathrm{M})$ in presence of different concentrations of OS for $24 \mathrm{~h}$ 


\section{Conclusion}

The present work reports a first approach on the optimization of the extraction of total phenolic compounds by microwave and by conventional methods from olive stones of native Algerian cultivars. Application of Box-Behnken design was judged to be a useful instrument to estimate the extraction parameters effect for optimizing the extraction of TPC. MAE was more efficient for the extraction of bioactive compounds. In addition, we studied antioxidant and anti-inflammatory activities of the obtained OS extracts. The results revealed that olive stones cultivars are a suitable plant material for potential further use as antioxidants in food, cosmetic and pharmaceutical applications. In particular, Achemlale and Atefah varieties presented the more effective anti-oxydant and antiinflammatory properties. The use of olive stones will allow reducing the amount of disposed by-products. Therefore, the promising enhanced use of these by-products offers a new opportunity for the promotion of the olive culture and opens a better exploitation of olive fruits stones.

Acknowledgements We thank the Ministry of Higher Education and Scientific Research, Algeria for providing the Algerian - French Scholarship. We would like to thank all members of MIB laboratory at the ISVV of Bordeaux (France) for their precious help.

\section{Declarations}

Conflict of interest The authors declare that they have no known competing financial interests or personal relationships that could have appeared to influence the work reported in this paper.

\section{References}

1. M.A. Martínez-González, A. Gea, M. Ruiz-Canela, The Mediterranean diet and cardiovascular health: a critical review. Circ. Res. 124(5), 779-798 (2019)

2. L. Verberne, A. Bach-Faig, G. Buckland, L. Serra-Majem, Association between the Mediterranean diet and cancer risk: a review of observational studies. Nutr. Cancer 62(7), 860-870 (2010)

3. M.C. Mentella, F. Scaldaferri, C. Ricci, A. Gasbarrini, G.A.D. Miggiano, Cancer and Mediterranean diet: a review. Nutrients 11(9), 2059 (2019)

4. Y. Orihara, Y. Ebizuka, Production of Triterpene Acids by CellSuspension Cultures of Olea Europaea. Olives and Olive Oil in Health and Disease Prevention (Elsevier, Amsterdam, 2010), pp. 341-347

5. Ilbert H. Produits du terroir méditerranéen: conditions d'émergence, d'efficacité et modes de gouvernance (PTM: CEE et MG), projet FEMISE, rapport final, Juin 2005. INAO. Appelations d'origine et paysages. 2006.

6. A. Romani, N. Mulinacci, P. Pinelli, F.F. Vincieri, A. Cimato, Polyphenolic content in five tuscany cultivars of Olea europaea L. J. Agric. Food Chem. 47(3), 964-967 (1999)
7. E. Ragazzi, G. Veronese, A. Guiotto, Demethyloleoeuropeine, new glucoside isolated from ripe olives. Anal. Chim. 63(1-2), 13-20 (1973)

8. A. Vazquez Roncero, E. Graciani Constante, D.R. Maestro, Phenolic compounds in olive fruits. I. Polyphenols in pulp. Grasas Aceites. 25, 269-279 (1974)

9. G. Vlahov, Flavonoids in three olive (Olea europaea) fruit varieties during maturation. J. Sci. Food Agric. 58(1), 157-159 (1992)

10. P.S. Rodis, V.T. Karathanos, A. Mantzavinou, Partitioning of olive oil antioxidants between oil and water phases. J. Agric. Food Chem. 50(3), 596-601 (2002)

11. A. Agourram, D. Ghirardello, K. Rantsiou, G. Zeppa, S. Belviso, A Romane et al., Phenolic content, antioxidant potential, and antimicrobial activities of fruit and vegetable by-product extracts. Int. J. Food Prop. 16(5), 1092-1104 (2013)

12. G. El-Baroty, M. Khalil, S. Mostafa, Natural antioxidant ingredients from by-products of fruits. Am. J. Agric. Biol. Sci. 9(3), 311-320 (2014)

13. D. Ryan, K. Robards, Critical review. Phenolic compounds in olives. Analyst 123(5), 31R-44R (1998)

14. D. Ryan, K. Robards, S. Lavee, Changes in phenolic content of olive during maturation. Int. J. Food Sci. Technol. 34(3), 265-274 (1999)

15. J.-R. Morelló, S. Vuorela, M.-P. Romero, M.-J. Motilva, M. Heinonen, Antioxidant activity of olive pulp and olive oil phenolic compounds of the Arbequina cultivar. J. Agric. Food Chem. 53(6), 2002-2008 (2005)

16. K. Ameer, H.M. Shahbaz, J.H. Kwon, Green extraction methods for polyphenols from plant matrices and their byproducts: a review. Compr. Rev. Food Sci. Food Saf. 16(2), 295-315 (2017)

17. J. Song, D. Li, C. Liu, Y. Zhang, Optimized microwave-assisted extraction of total phenolics (TP) from Ipomoea batatas leaves and its antioxidant activity. Innov. Food Sci. Emerg. Technol. 12(3), 282-287 (2011)

18. M.N. Safdar, T. Kausar, M. Nadeem, Comparison of ultrasound and maceration techniques for the extraction of polyphenols from the mango peel. J. Food Process. Preserv. 41(4), e13028 (2017)

19. S. Georgé, P. Brat, P. Alter, M.J. Amiot, Rapid determination of polyphenols and vitamin C in plant-derived products. J. Agric. Food Chem. 53(5), 1370-1373 (2005)

20. A. Djeridane, M. Yousfi, B. Nadjemi, D. Boutassouna, P. Stocker, N. Vidal, Antioxidant activity of some Algerian medicinal plants extracts containing phenolic compounds. Food Chem. 97(4), 654660 (2006)

21. M.S. Blois, Antioxidant determinations by the use of a stable free radical. Nature 181(4617), 1199 (1958)

22. A. Dávalos, C. Gómez-Cordovés, B. Bartolomé, Extending applicability of the oxygen radical absorbance capacity (ORAC- fluorescein) assay. J. Agric. Food Chem. 52(1), 48-54 (2004)

23. M. Oyaizu, Studies on products of browning reaction. Jpn. J. Nutr. Diet. 44(6), 307-315 (1986)

24. T.C. Dinis, V.M. Madeira, L.M. Almeida, Action of phenolic derivatives (acetaminophen, salicylate, and 5-aminosalicylate) as inhibitors of membrane lipid peroxidation and as peroxyl radical scavengers. Arch. Biochem. Biophys. 315(1), 161-169 (1994)

25. Bonnaillie C, Salacs M, Vassiliova E, Saykova I. Etude de l'extraction de composés phénoliques à partir de pellicules d'arachide (Arachis hypogaea L.). 2012.

26. Mafart P, Béliard E. Techniques séparatives: Tehnique et Documentation;-Lavoisier; Apria; 1992.

27. I. Gülçin, Antioxidant activity of food constituents: an overview. Arch. Toxicol. 86(3), 345-391 (2012)

28. A. De. Bruno, R. Romeo, F.L. Fedele, A. Sicari, A. Piscopo, M. Poiana, Antioxidant activity shown by olive pomace extracts. J. Environ. Sci. Health B 53(8), 526-533 (2018) 
29. M. Naczk, F. Shahidi, Phenolics in cereals, fruits and vegetables: occurrence, extraction and analysis. J. Pharm. Biomed. Anal. 41(5), 1523-1542 (2006)

30. R. Chirinos, H. Rogez, D. Campos, R. Pedreschi, Y. Larondelle, Optimization of extraction conditions of antioxidant phenolic compounds from mashua (Tropaeolum tuberosum Ruíz \& Pavón) tubers. Sep. Purif. Technol. 55(2), 217-225 (2007)

31. M.A. Al-Farsi, C.Y. Lee, Optimization of phenolics and dietary fibre extraction from date seeds. Food Chem. 108(3), 977-985 (2008)

32. W. Tinsson, Plans d'expérience: Constructions et Analyses Statistiques (Springer, New York, 2010)

33. S. Chan, C. Lee, C. Yap, W.W. Aida, C. Ho, Optimisation of extraction conditions for phenolic compounds from limau purut (Citrus hystrix) peels. Int. Food Res. J. 16(2), 203-213 (2009)

34. D.L. Luthria, Influence of experimental conditions on the extraction of phenolic compounds from parsley (Petroselinum crispum) flakes using a pressurized liquid extractor. Food Chem. 107(2), 745-752 (2008)

35. C. Liyana-Pathirana, F. Shahidi, Optimization of extraction of phenolic compounds from wheat using response surface methodology. Food Chem. 93(1), 47-56 (2005)

36. D. Uma, C. Ho, W.W. Aida, Optimization of extraction parameters of total phenolic compounds from henna (Lawsonia inermis) leaves. Sains Malaysiana. 39(1), 119-128 (2010)

37. C. Yap, C. Ho, W.W. Aida, S. Chan, C. Lee, Y. Leong, Optimization of extraction conditions of total phenolic compounds from star fruit (Averrhoa carambola L.) residues. Sains Malaysiana. 38(4), 511-520 (2009)

38. V. Mandal, Y. Mohan, S. Hemalatha, Microwave assisted extraction-an innovative and promising extraction tool for medicinal plant research. Pharmacogn. Rev. 1(1), 7-18 (2007)

39. B. Lapornik, M. Prošek, A.G. Wondra, Comparison of extracts prepared from plant by-products using different solvents and extraction time. J. Food Eng. 71(2), 214-222 (2005)

40. B. Lee, J. Jung, Y. Choi, Optimization of microwave-assisted extraction process of Rehmannia Radix preparata by response surface methodology. Food Eng. Progr. 9, 283-290 (2005)

41. Santos-Buelga, C., Gonzalez-Manzano, S., Dueñas, M., GonzalezParamas, A.M.: Extraction and isolation of phenolic compounds. Natural products isolation. pp. 427-64 (2012)

42. M. Careri, L. Elviri, A. Mangia, M. Musci, Spectrophotometric and coulometric detection in the high-performance liquid chromatography of flavonoids and optimization of sample treatment for the determination of quercetin in orange juice. J. Chromatogr. A 881(1), 449-460 (2000)

43. M.H. Alu'datt, I. Alli, K. Ereifej, M. Alhamad, A.R. Al-Tawaha, T. Rababah, Optimisation, characterisation and quantification of phenolic compounds in olive cake. Food Chem. 123(1), 117-122 (2010)

44. G. Spigno, L. Tramelli, D.M. De. Faveri, Effects of extraction time, temperature and solvent on concentration and antioxidant activity of grape marc phenolics. J. Food Eng. 81(1), 200-208 (2007)

45. A. Telli, N. Mahboub, S. Boudjeneh, O. Siboukeur, F. Moulti-Mati, Optimisation des conditions d'extraction des polyphénols de dattes lyophilisées (Phoenix dactylifera L.) variété ghars. Annales des Sciences et Technologie. 2(2), 107-114 (2010)

46. L.G. D’Alessandro, P. Vauchel, R. Przybylski, G. Chataigné, I. Nikov, K. Dimitrov, Integrated process extraction-adsorption for selective recovery of antioxidant phenolics from Aronia melanocarpa berries. Sep. Purif. Technol. 120, 92-101 (2013)

47. J.A. Larrauri, P. Rupérez, F. Saura-Calixto, Effect of drying temperature on the stability of polyphenols and antioxidant activity of red grape pomace peels. J. Agric. Food Chem. 45(4), 1390-1393 (1997)
48. B. Zhang, R. Yang, C.-Z. Liu, Microwave-assisted extraction of chlorogenic acid from flower buds of Lonicera japonica Thunb. Sep. Purif. Technol. 62(2), 480-483 (2008)

49. C. Proestos, M. Komaitis, Application of microwave-assisted extraction to the fast extraction of plant phenolic compounds. LWT-Food Sci. Technol. 41(4), 652-659 (2008)

50. D. Spigno De Faveri, Microwave-assisted extraction of tea phenols: a phenomenological study. J. Food Eng. 93(2), 210-217 (2009)

51. M. Elbir, A. Amhoud, M. Mbarki, F. Visioli, Antioxidant activity of a crude preparation rich in phenolic compounds from the olive stones of two Moroccan cultivars, a preliminary study. Curr. Topics Nutraceut. Res. 12(1-2), 9-12 (2014)

52. F. Zaidi, N. Hassissene, H. Allouache, M. Kichou, S. Ourdani, K. Rezki et al., Les composes phenoliques, facteur limitant du grignon d'olive chez les ruminants. Revue de Medecine Veterinaire. 160(2), 67 (2009)

53. H. Hannachi, W. Elfalleh, S. Marzouk, Oil, protein, antioxidants and free radical scavenging activity of stone from wild olive trees (Olea europaea L.). Pak. J. Pharm. Sci. 26(3), 503-510 (2013)

54. S. Burda, W. Oleszek, C.Y. Lee, Phenolic compounds and their changes in apples during maturation and cold storage. J. Agric. Food Chem. 38(4), 945-948 (1990)

55. C.H. Crisosto, V. Bremer, L. Ferguson, G.M. Crisosto, Evaluating quality attributes of four fresh fig (Ficus carica L.) cultivars harvested at two maturity stages. HortScience 45(4), 707-710 (2010)

56. J.A. Kennedy, Y. Hayasaka, S. Vidal, E.J. Waters, G.P. Jones, Composition of grape skin proanthocyanidins at different stages of berry development. J. Agric. Food Chem. 49(11), 5348-5355 (2001)

57. S.M. Cardoso, S. Guyot, N. Marnet, J.A. Lopes-da-Silva, C.M. Renard, M.A. Coimbra, Characterisation of phenolic extracts from olive pulp and olive pomace by electrospray mass spectrometry. J. Sci. Food Agric. 85(1), 21-32 (2005)

58. A. Ranalli, S. Contento, L. Lucera, M. Di. Febo, D. Marchegiani, V. Di. Fonzo, Factors affecting the contents of iridoid oleuropein in olive leaves (Olea europaea L.). J. Agric. Food Chem. 54(2), 434-440 (2006)

59. A. De. Bruno, R. Romeo, A. Piscopo, M. Poiana, Antioxidant quantification in different portions obtained during olive oil extraction process in an olive oil press mill. J. Sci. Food Agric. 101(3), 1119-1126 (2021)

60. M. Nadour, Extraction, Caractérisation Des Polysaccharides et Des Polyphénols Issus Des Sous Produits Oléicoles (Universite Mouloud MAMMERI, Valorisation Des Polysaccharides à Visée Alimentaire, 2015)

61. A. Jalili, S. Alipour, A. Sadegzadeh, Antioxidant and antiradical activities of phenolic extracts from Juglanse regia hulls and shells. Int Res J Plant Sci. 1, 282-289 (2011)

62. I. Stanisavljević, S. Stojičević, D. Veličković, V. Veljković, M. Lazić, Antioxidant and antimicrobial activities of Echinacea (Echinacea purpurea L.) extracts obtained by classical and ultrasound extraction. Chin. J. Chem. Eng. 17(3), 478-483 (2009)

63. A. Ben Mansour, E.A. Porter, G.C. Kite, M.S. Simmonds, R. Abdelhedi, M. Bouaziz, Phenolic profile characterization of Chemlali olive stones by liquid chromatography-ion trap mass spectrometry. J. Agric. Food Chem. 63(7), 1990-1995 (2015)

64. G. Rodríguez, A. Lama, R. Rodríguez, A. Jiménez, R. Guillén, J. Fernández-Bolaños, Olive stone an attractive source of bioactive and valuable compounds. Biores. Technol. 99(13), 5261-5269 (2008)

Publisher's Note Springer Nature remains neutral with regard to jurisdictional claims in published maps and institutional affiliations. 